Presented at the Particle Accelerator Conference, Chicago, Ill., March 1-3, 1971
Conf $-710308--15$

\title{
DIGITAL CONTROL OF BEVATRON ACCELERATION CYCLE
}

Don M. Evans and Fred H. G. Lothrop

February 1971

AEC Contract No. W-7405-eng-48
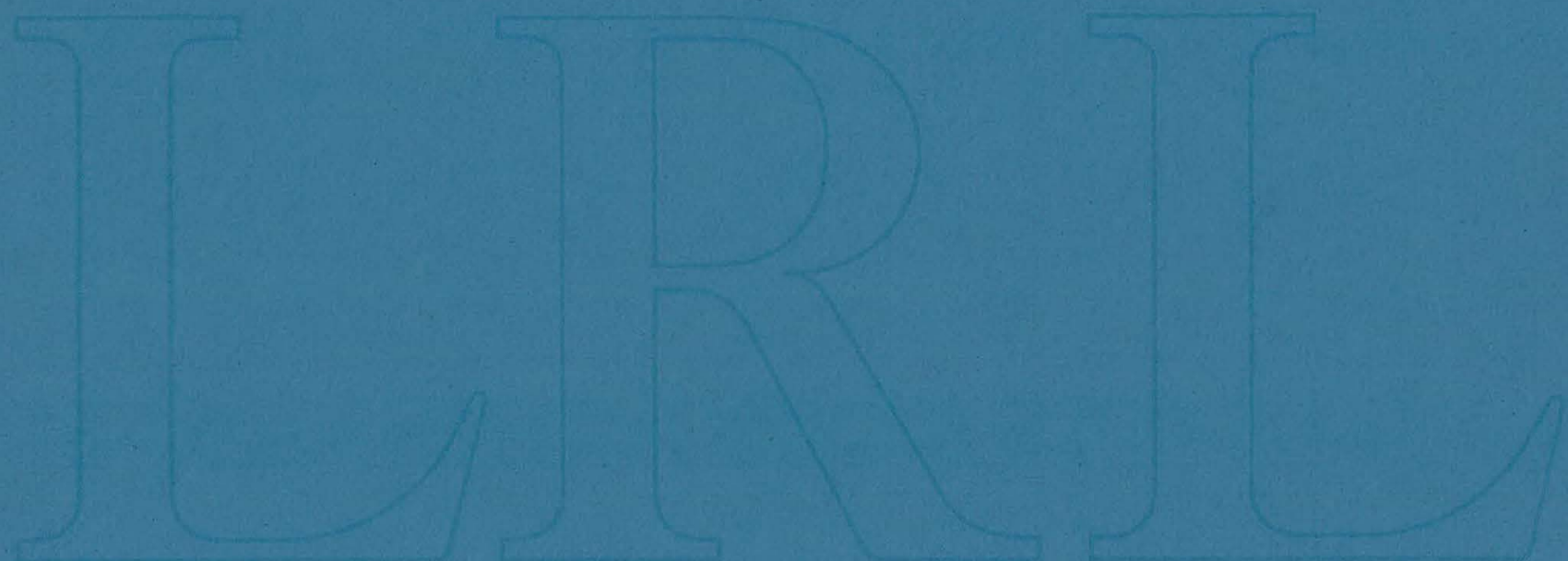

\section{LAWRENCE RADIATION LABORATORY UNIVERSITY of CALIFORNIA BERKEIEY}




\section{DISCLAIMER}

This report was prepared as an account of work sponsored by an agency of the United States Government. Neither the United States Government nor any agency Thereof, nor any of their employees, makes any warranty, express or implied, or assumes any legal liability or responsibility for the accuracy, completeness, or usefulness of any information, apparatus, product, or process disclosed, or represents that its use would not infringe privately owned rights. Reference herein to any specific commercial product, process, or service by trade name, trademark, manufacturer, or otherwise does not necessarily constitute or imply its endorsement, recommendation, or favoring by the United States Government or any agency thereof. The views and opinions of authors expressed herein do not necessarily state or reflect those of the United States Government or any agency thereof. 


\section{DISCLAIMER}

Portions of this document may be illegible in electronic image products. Images are produced from the best available original document. 
This report was prepared as an account of work sponsored by the United States Government. Neither the United States Atomic Energy the United States nor of their employees, nor any of Commission, nor any of their er their employees, their contractors, subcontractors, or theis, or assumes any makes any warranty, express or implied, or assuracy, comlegal liability or responsibility for the accuracy, com pleteness or usefulness of any information, apparatus product or process disclosed, or represent
u tot infringe privately owned rights.

\section{DIGITAL CONTROL OF BEVATRON ACCELERATION CYCLE}

Don M. Evans and Fred H. G. Lothrop

Lawrence Radiation Laboratory

Berkeley, California

\section{Sumary}

Control of the Bevatron acceleration system had been entirely analogue until developments in proton extraction techniques required substantial reduction of hum and noise during the acceleration cycle. The decision was made to employ a digital processor to control the acceleration cycle. An algorithm is developed which allows introduction of radial-feedback data into the digital processor and the real-time error signal is combined with arbitrary field dependent functions for transmission to the existing master oscillator.

A high common-mode rejection digltal system is utilized to enter the resultent control data directly into the master-oscillator environment before conversion into the required analog reference for frequency modulation. A comprehensive hardware "calculator" provides a continuous curve of digital representations to be sent along to the oscillator.

The paper describes implementation of these facilities and the development of operator-oriented interface to capitalize upon the flexibilities inherent within a digitaly oriented system.

\section{History}

Proton acceleration at the Bevatron is accomplished by the application to an accelerating electrode of an $r f$ voltage varying in frequency from $500 \mathrm{kHz}$ to $2.5 \mathrm{MHz}$, the first harmonic of the particle rotational frequency. For this frequency sweep we saturate a ferrite core with a current proportional to the mognet1c guide field value. This core also camprises the magnetic material for the inductance portion of an LC tank circuit in our master oecillator. The capacitance portion is comprised of fixed capacitors, an alr-variable capacitor, and voltage-variable capacitors. Coarse frequency tracking of the gulde rield is done by the inductance, and fine adjustments are made by modulating the voltage applied to the voltage-variable capacitors, to which we will refer as the modulator.

Fine frequency adjuatment voltages are supplied by four types of input: (1) the Tritec, wh1ch supplies the basic open-loop correction signal, (2) the Autotrack, which is the major element of a closed loop radial position feedback system. (3) the phase loop, which is a closed loop system damping syachrotron oscillations, and (4) small perturbation signals in the form of halfsine waves and trapezoldal vaveforms.

Fig. I depicts the orrangement of components we use for frequency conirol at the Bevatron. The mixers are linear, their output being the algebraic sum of the input voltages. The waveforms of the various tracking signels are shown in Fig. 2 and 3 . The Tritec wave form is shown at the top of $F 1 g .2$, and an example of our sine and trapezoid waveforms is shown at the bottom. Fig. 3 will give sone idea of the combinations available from the waveform generators.

Work performed under the auspices of the Atomic Energy Commission.
Analogue-vigital Metarorphosis

Studies begun about four years ago have culminated in the production of a resonant-extraction proton beam of bigh efficiency (80-90\%). Fundamental to the success of the resonant extraction system was the eradication of noise and hum present in the modulating components of the frequency control system, which were adequately small for previous operation but too large for the new mode. Unvanted s1gnal sources into the modulator are the result of ground current paths in the single-ended circuitry together with the expected small mounts of power supply ripple introduced by each source. Noise and ripple considerations in this case point toward a serlous evaluation of all possible high-rejection capability technologies. A digital system is attractive in this instance, because of the potential of belng able to provide most or all of the necessary functions in digital sortwere and converting the result to a single analogue value close within the master-oscillator environment and with the signal referenced only to the oscillator. This situation entirely removes the noise and ripple problem so long as the one analgue source is carefully constructed and so long as the interface provides high isolation between digital and analogue realms.

Digitizing the inputs to the modulator in this case implied that all signals to be used for frequency modulation would either be generated or processed by means of a digital computer and interfece circuitry. With one exception, all of our inputs are susceptible to the digital concept as applied at the Bevatron. This one exception is the "phese-loop" which is to fast a system for our capabilities at this time.

Digltal facilities at the Bevatron include four PDF- 8 processors. Two are currently being used to control the magnetic guide field and the external beam transport magnet currents. The third is dedicated to $r f$ system control, and the fourth is used as a standby, debugging, and miscellaneous calculations machine. Experience leads us to believe that for these processors, a I millisecord update rate is about optimum, so signals being generated by these devices should be required to have no more than a $500 \mathrm{~Hz}$ component. Thus the phase loop is ruled out because its highest gain region is in the 1 to $2 \mathrm{kHz}$ range. Analogue provision has been made in the frequency modulator to accept this one input.

\section{The Task}

Work was begun to determine how the beam radius feedback loop could be incorporated into the digital syster. At the same time, software development was started to generate the perturbations used for fine tracking through the solution of one or more equations, preferably a quadratic or cubic.

It appeared clear after the initial decisions vere made that this digital system must be made so that it would be attractive to the men who operate the Bevatron. Therefore, we have undertaken to design a control and display interface systen which will be versatile and appropriate to the type of process peculier to accelerators. 
The task before us, as it was finally set down, then, was this: to design a noise-free frequency modulator, using digital facilities wherever possible, having the same control capability as the previous analogue unit, if not greater, and having the capability of being operated easily by the Bevatron staff. An ancillary task, fascinating in itself, is the design of the monitoring syster, now in its final stages. This monitoring system will accept computer output or analog input and vill present a real-time display of lines or text on a color TV monitor. Display presented to the operating staff will include dynamic circulating bear intensity measurements, monitor telescope signal, the tracking perturbation signals, and the beam position with respect to the centerline of the Bevatron vacuum tank.

\section{Solutions}

Radial. Feedback. The Autotrack technique used for the past 10 years is certainly nothing new. Looking again at $\mathrm{Flg}$. 1 , 8 ignals from split pick-up electrodes are brought to the control area, where the sum and difference are taken by the appropriate amplifiers. Normalization against beam intensity variations is then done in a pair of AGC amplifiers in which the gains are inversely proportional to the amplitude of the sum signal. The outputs of these amplifiers then applied to a synchronous detector and de smplifier, so that sign and magnitude voltage information is avallable to feed back to the frequency modulator. The equation which is solved by this analogue system 1s:

$$
\begin{aligned}
& v_{E}=\gamma\left(\frac{v_{a}-v_{b}}{v_{a}+v_{b}}\right) . \\
& v_{a}=G B \frac{x}{D}, v_{b}=g(1-0)\left(2-\frac{x}{D}\right)
\end{aligned}
$$

$B=$ beam to pick-up electrode transfer function, rolts/protop

$B=$ attenuator transfer runction

$x=$ beam displacement $v i t h$ respect to $D, 0 \leq x \leq D$, in.

$v=$ width of sensitive area of the pick-up plates, in.

$Y=$ system transfer function, volts.

Expansion of the terms to include all the variables yields:

$V_{E}=\gamma\left[\frac{\beta-(1-x / D)}{B\left(\frac{2 x}{D}-1\right)+(1-x / D)}\right]=2 \gamma\left(\beta-\left(1-\frac{x}{D}\right)\right) \quad x / D=1 / 2$

Normalization with respect to beam intensity is not accurate over the $f$ lil range of $x / D$. When $x / D=1 / 2$ the nornalization is good, and $B$ may vary over its rwl range from 0 to. 1 with no effect on the normalization. This transfer function, $B$, is important to the analogue system because it represents tbe sumning polnt function in this fecdbeck system.

Inasrouch as the radius on which we want to guide is not fixed during the acceleration cycle, and may not be the geometric centerline at all, the reference for the system must be variable in eccordance with our wishes, and manipulation of $B$ by a modulating voltage will, in effect, vary the reference for the system.

Computer-based duplication of the analogue Autotrack system allows the same dynamic range and at the same time permits the proper action of a reference summing point in this reejback loop, and accurate normalzation to beam intensity variations. The equation to be solved by the digital system is of the form
$\left.V_{E}=\left(\frac{V_{x}-V_{y}}{V_{x}+V_{y}}\right)+c\right)$ where $c$ is a reference number, and

$v_{x}$ and $v_{y}$ are outer and lnner radius sequal voltages.

F1g. 4 is the block diagram of the frequency control system using digital components to supply to the master oscillator all of the signals previously generated by our analogue system with the exception of the phase feedback loop.

Acturl on-the-accelerator tests of th1s computerbased feedback control system vere hlghly successful. Beam steering capability was excellent, and losses during acceleration were what we expected. At that time ve did not bave proper conditioning of the input signals form the radial pick-up electrodes, so that the system was somewhat sensitive to beam bunch shape, and the intensity indication of the bean was not accurate.

He now have avallable two devices which improve our rcsolution and accuracy considerably. The first is a signal conditioning unit which detects the area under the electrode voltage vaveform and converts this to a slowly varying de signal, so that bunch shape changes will have a minimal effect on the operation of the feedback system.

The second device to ald us is a 64-channel analog-to-digital converter facility.

To achieve data acquisition in as near a realtime sense as possible, the $A D C$ has been maintained as a sortware - control, led random - access device. To allov full $0.1 \%$ accuracies with fast-sleving input signals, the total acquisition and conversion must be accomplished within 2. Ousec. Fest-retting Silicon-m Gate MOS analog switches are employed for random selection from the 64 integrated-circuit conditioning amplifiers. The gain of each amplifier channel is variable over 60dB. Conversion is accomplished through successive approximation techniques at 100 nanoseconds per blt. The overall result is that eddrésilng, acquisition, conversion, and finally inputting the converted data, all in one input/output oyole of tho central processor.

\section{Calculation}

Experlence gained in the implementation of other control systems associated with the. Bevatron has indicated that one of the limiting factors in control task size is the available time for arithmetic calculations. The effective time is a Punction of (1) the complexity of the calculation, (2) the iterations required to scan the number of elements under control, (3) the number of autonomous functions contributing to the final control values (4) the extent of the "bookkeeping" required to manipulate the parameters involved in each of the above.

Operator requests for radial excursions of the circulating beam can include several overlapping functions. The arbitrary functions offered initially in the digital facility closely duplicate those previously implemented in hardware function-generators. These include parabolic and trapezoidal functions, and are calculated individually from paraneter tables prepared from operator-spectfied numerical values.

Parabolic functions of the form: $Y=x(K-A x)+B$ are calculated iteratively using, the tebulated data and the current value of the independent variable. 
Trapezoldal functions are handled somewhat differently in that the straight-line segments are retained in memory as end-point coordinates and calculatlons to reconstruct the line segments are interpolations. The simplified form of these solutions is: $y=[(x-N)(L-M) /(J-N)]+P$.

It is possible to overlap these several functions, thus causing the net reference word to be the sum of the result of each of the several independent solutions.

The actual control word calculated for transmission to the DAC is then the sum of the closed-loop calculation, whose form was shown elsewhere, and the open-loop coarse correction curve, separately calculated. The coarse correction curve is made of several zones, each with an exponential function and in some cases with the additional requirement that end point slopes be matched. These exponentials are reduced to simple difference equations of the form

$$
v=v_{n-1}+(A+B) / C \text {. }
$$

Common Algorithm. An analysis of these separate and quite individual functions allows expansion to a common all-inclusive "general form" calculation: $Y=\frac{(A B+C)(D+E)}{F+C}+H$. In the processors in use at the Bevatron, the most signiffcant time periods expended in calculations are associated with manipulating signed variables into, through and successfully out of multiplication and division routines. The hardware facilities for such manipulations within the processors are slow.

It has become feasible to approach the "general form" calculation from a programmable micro-processor hardware aspect. A parallel-multiplier-calculator has been created to provide enormous savings in time and software complexity.

\section{The Calculator}

Although a micro-processor exhibits savings in time over a software approach, we have concluded that the full complement of arithmetic operations required to implement the general-form equation is rarely employed. For this reason, the micro-processor is programmable in the sense that a code word, heading a list of variables, defines the actual sequence of arithmetic operations to be employed. The code vord Indicates the variables present as well as the operations to be performed. Thus, if the required camputation is: $(A \times B)+C$; the code word indicates that the division and several other incidental operations are not to be performed. The average time required for calculations is then shortened to conform more closely with the average complexity of calculations.

This calculator 15 accessed by the central processor through a direct-memory access channel, thereby freejns software from any responsibility after the list of variables is once prepared. Results of the calculations are then added to the same l1st of variables.

MSI logic was used throughout the calculator to reduce hardware density to a practical level. A parallel multiplier was created with a 300 nanosecond worst-case propagation time to racilitate both the required multiplication and a successive approximation division. The utilization of common hardware in both operations reduces cost effectively. As all arithmetic operations are signed, the necessary 2 's complement generators have been developed to allow complete freedom of software data manipulation. In order to obtain maximum signlficance from the results of a multiplication, a parallel scaling element is utilized to extract from the products any desired portion of the double-precision result.

\section{Digital Tranmission Technique}

Accelerator environments contain a reasonable number of analog signal sources. Changing magnetic fields, rf fields usually sweeping in frequency as well as pulsed microwave tank structures abound. Spark gaps and circulating bean currents add their contributions. Though vitally necessary to the acceleration of charged particles, these electromagnetic fields represent only disastrous noise to a digital data transmission system. To combat these noise sources, we have developed an error-detection error-correction serial differential transmission system. Virtually all of the digital data is presently transported in the PDM mode using this new technique. Error detection and correction is achieved through the generation, transmission, regeneration and comparison of a full Hamming code over the data and address bits included within the transmission.

Differential transmitters and receivers available in integrated circuit form have substantially improved the decoupling of data from noise. Because several volts may separate building ground points within an accelerator area it is necessary to have at least $80 \mathrm{~dB}$ of common mode rejection to lend credibility to a 12-bit system. Additionally, rejection must exist across the interface between logic lines and the analog levels derived from them in a controlled device. Sixtyfive $d B$ of isolation is adequate in these applications.

Data words on the digital lines into the master oscillator environment are applied as the input to a 12-bit digital to enelog converter (DAC) which generates a low-noise, highly stable current proportional to the numerical value contained within the data word. This current is summed with the analog contribution from the phase loop at an operational amplifier. The resultant voltage created, proportional to the algebralc sum of the input currents, is applied to the voltage controlled capacitors within the tank circuit of the master oscillator.

\section{Operator Controller}

Initial efforts have resulted in an operator interface (Fig. 5: with separate keyboards for alpha/ numeric function requests, and light-emitting-diode (LED) numerical reacouts for computer feedback. As several components of the various steering parameters must be varied simultaneously, four separate variablerate lever-switch actuated controls are employed to change their numerical values. To further lighten the software load within the computer, all input/ output data essociated with the controller is in binary format. All conversions compatible with alpha/numerlc readouts are made vitinin the hardware of the controller. Almost complete in the design state is a new concept in Braphic display. A line-printer has been installea to communicate directly with the four computers or with the peripheral memory associated with the video-scan text display currently under developnent.

\section{Field vs Time}

A change in concept at the Bevetron, though minor in significance at first glance, appears to be assuming large proportions. Since the incorpcration of a highresolution digital guide field integiator and the addition of a residual field measurenent device, more emphasis has been placed on absolute field value with 
a gradual decline in time-oriented concepts. Previous function-generators in radial control, as an example, were time-dependent functions, whereas all new functions are guide-field dependent. This has further reoriented our thinking such that the time-honored current markers ("I-pips") are being replaced with field-narkers representing integer kilogeuss field values. This appears to be only reasonable, as protons, and therefore, the entire accelerator, exist in a time-reference only incidentally, while field values uniquely determine the energy/radius relationship and thus remove still another anomaly and source of jitter and instability in accelerator operation.

\section{Conclusions}

Necessity is a mother of invention, we are told, and in the case of the Bevatron, it has turned out to be true. The advent of a resonant extraction system for this machine forced us, happily, into a new era of accelerator control, in which the excellent inherent resolution of the digltal gystem has meant for us a new precision and flexibility in operating the Bevatron. The most worthwhile practical advance has been in the area of beam delivery to the experimenters. With the new control technique, resonant extraction is a practical reality, enabling us to deliver more protons per unit time to our experimental facility, at a much more unfform rate, so we think it is permissible to say that we have improved the efficiency of the Bevatron markedly.

Perhaps a more fundamental and important advance has come from the interfacing of our very human operators with a high speed programable control system in what we believe to be a very attractive manner. Thew new controller, combined with the multitrace color display of numerous variables, will give our operators an extremely fast, flexible set of handles,with which to manipulate the circulating protons.

Or great convenience as a third consequence of our afgital systen technique is the notion that since many of the Bevatron parameters will be digitalized and capable of being handled by a central processor, we will have a bookkeeping system in step with modern time.

There has come to the Bevatron efficiency, elexbility, and convenience through digital control of the acceleration cycle which we believe to be significant, not because we used a computer to accomplist the goals, but because computers and other digital equipments are now capable of helping us to maintain and advance the state of the art. in the control of nuolcar acceleratuss.

\section{Acknowledgements}

Work on this project wes initiated througb the efforts of $Y$. Bacconier (now at CERN) and G. R. Lambertson. Continuing investigation into the requirements to be met are credited to H. Grunder and R. J. Force. Of great assistance in hardware development were J. B. Greer, D. E. Oldfather, R. Kilgore, F, C. Caldera, and $B$. Hordos. Program development was the responsibility of $R$. Belshe and J. R. Guggemos. $M$. Tekawa and $E$. Zajec were of great aid in coordination with the Bevatron Operating Group.

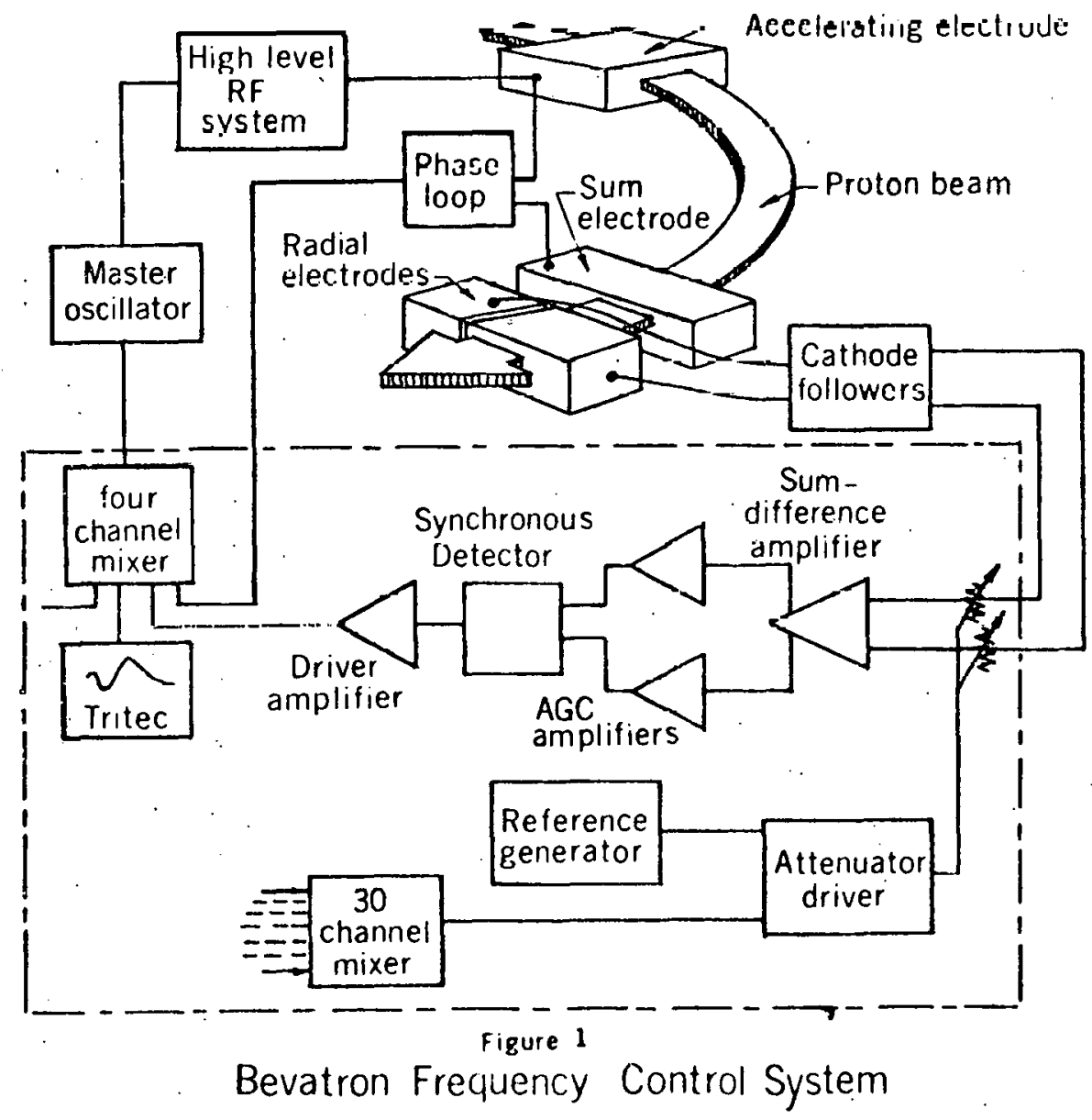




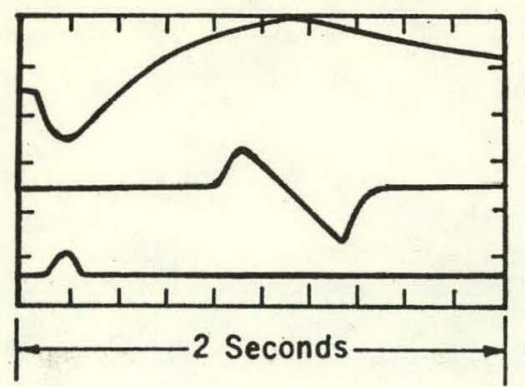

Figure 2

Tritec and Perturbation Signals

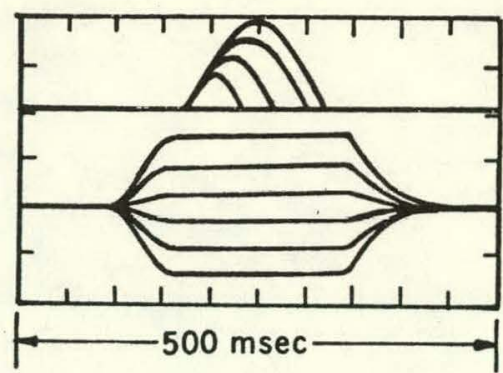

Figure 3

Some Waveforms Available for Modulation

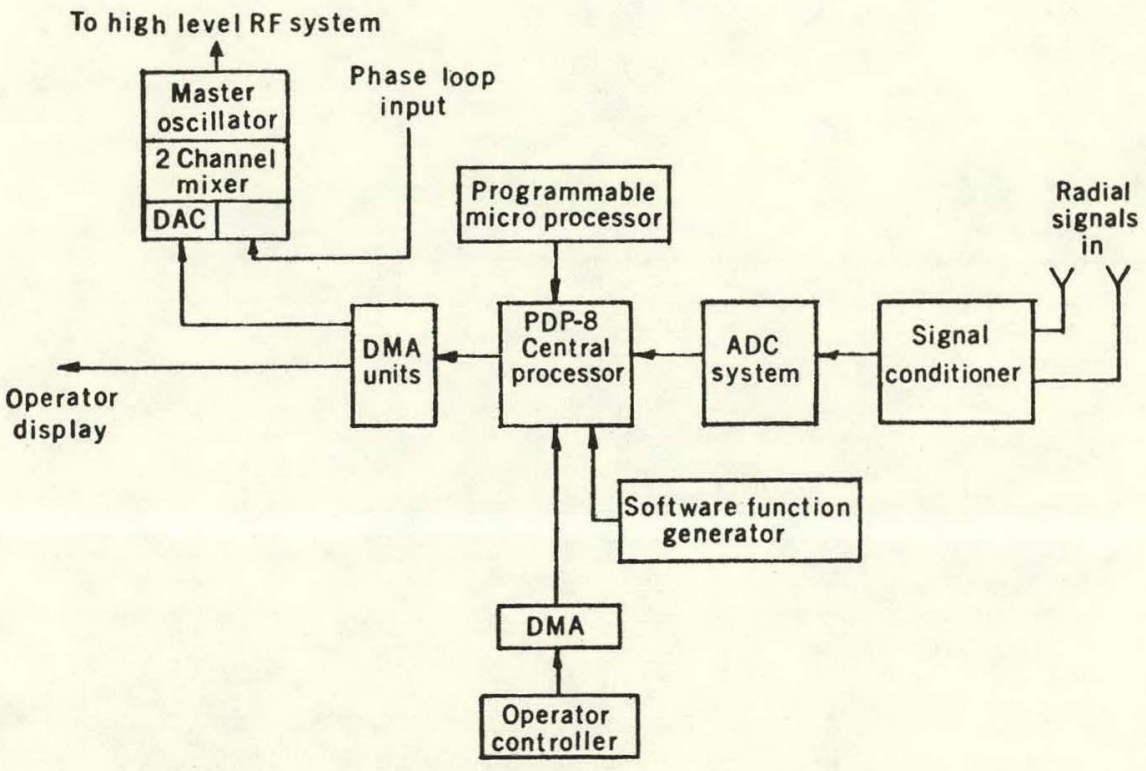

Figure 4

Digital Frequency Control Components

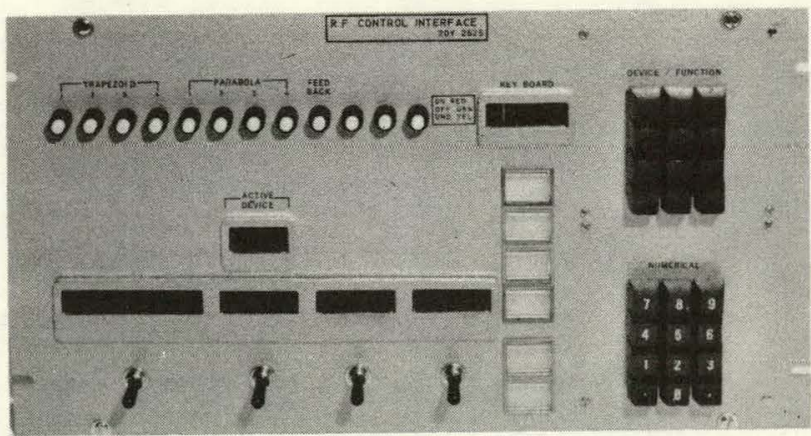

Figure 5 Operator Controller Unit 
This report was prepared as an account of work sponsored by the United States Government. Neither the United States nor the United States Atomic Energy Commission, nor any of their employees, nor any of their contractors, subcontractors, or their employees, makes any warranty, express or implied, or assumes any legal liability or responsibility for the accuracy, completeness or usefulness of any information, apparatus, product or process disclosed, or represents that its use would not infringe privately owned rights. 
